\title{
Differential ventilation in unilateral pulmonary artery occlusion
}

\author{
C. S. DARKE and T. W. AST T N ${ }^{1}$ \\ The Respiratory Function Unit, The Royal Infirmary, and the University Department of Medicine, \\ The Royal Hospital, Sheffield
}

A case is reported of complete isolated occlusion of the right pulmonary artery resulting in underperfusion of the right lung; this was confirmed radiographically and at thoracotomy. Bronchospirometry showed that there was a reduction of ventilation to the right lung. When this lung alone was supplied with a carbon dioxide rich mixture there was a shift of ventilation towards the normal pattern with reversion to the initial distribution when air breathing was resumed. Ventilation of the right lung with a low oxygen mixture failed to cause any shift of ventilation. The results confirm that the effects of pulmonary artery occlusion on differential ventilation which have been shown in animals also occur in man and provide further evidence that carbon dioxide can have a bronchodilator action in man.

The right lung normally receives a greater proportion of the inspired air than the left; in the supine posture approximately $55 \%$ of the ventilation goes to the right lung and $45 \%$ to the left (Bjorkman, 1934; Gaensler and Cugell, 1952; Bergan, 1952; Svanberg, 1957; Lillington, Fowler, Miller, and Helmholz, 1959).

In dogs there is a change in the distribution of ventilation when one pulmonary artery is occluded; a reduction in ventilation occurs in the affected lung and is accompanied by a corresponding increase in the opposite lung (Moore, Humphreys, and Cochran, 1934; Venrath, Rotthoff, Valentin and Bolt, 1952). The shift in ventilation can be prevented by ventilation of the affected lung with either a carbon dioxide or a low oxygen mixture (Severinghaus et al., 1961). It has been suggested that pulmonary artery occlusion reduces the alveolar carbon dioxide tension in the affected lung which in turn increases the airways resistance of that lung and thus alters the distribution of ventilation. The prevention by carbon dioxide of the shift in ventilation could thus be explained.

In man, also, the temporary occlusion of one pulmonary artery by a balloon has reduced the ventilation of the affected lung, and the administration of carbon dioxide to the latter has prevented these changes in ventilation (Swenson, Finley, and Guzman, 1961).

Although this effect has been demonstrated in experiments on normal man, there have been few

1Reprint requests to T. W. A., Department of Medicine, The Royal Hospital, Sheffield S13 SR, Yorks. studies of the spontaneously occurring condition which can arise as a result of pulmonary embolism. Davison, Armitage, and Mcllveen (1956) made bronchospirometric studies in a patient with bilateral pulmonary emboli but in whom the left lung was slightly more affected than the right; the distribution of ventilation was normal. Sadoul et al. (1962) found an abnormal distribution of ventilation in a patient with pulmonary embolism of the left lung. Wilhelmsen et al. (1963) reported reduction of ventilation to a right lung which had received pulmonary emboli; the distribution was $50 \%$ to each lung. Scholzman, Kerby, and Ruth (1971) reported a reduction of the tidal volume in the left lung and increased tidal volume in the right lung of a patient with a long standing thrombosis of the left main pulmonary artery. The effect of carbon dioxide inhalation on the distribution of ventilation was not investigated in any of these studies.

The following report is of a patient who had a pulmonary embolus occluding the right main pulmonary artery and in whom the effects of inhaling first carbon dioxide and then a low oxygen mixture were investigated.

\section{CASE HISTORY}

A.H., a school caretaker aged 52 years, was admitted to the Royal Infirmary, Sheffield, in 1966 for investigation of severe and progressive dyspnoea over the previous seven years. He was unable to walk upstairs and 
could manage only 200 yards on the level before stopping for breath.

The early history of this disorder began in 1946 when he developed deep venous thrombosis in both lower limbs. This was followed by the appearance of varicose veins for which ligature and stripping was eventually carried out on the left side and a year later he underwent a similar procedure on the right leg. Chronic oedema of both legs ensued. Large superficial varicosities developed in the right groin, extending up to the right lateral wall of the abdomen and eventually connecting with the superior epigastric veins. Blood flowed upwards within the varicosities. Mild varicosities were noted also over the lower part of the left side of the abdomen (Fig. 1). Surprisingly little disability was felt for a number of years but in 1959 and again in 1966 he suffered attacks of chest pain, diagnosed as 'pleurisy and pneumonia'. On the latter occasion there had been a small haemoptysis.

Clinical examination in April 1966 was notable for the marked tachypnoea and hyperventilation at rest which became more obvious on slight exercise. Central cyanosis at rest also deepened on exertion. There was no orthopnoea. Breath sounds were vesicular and of normal intensity apart from some reduction over the right lower lobe. The pulse was regular and the blood

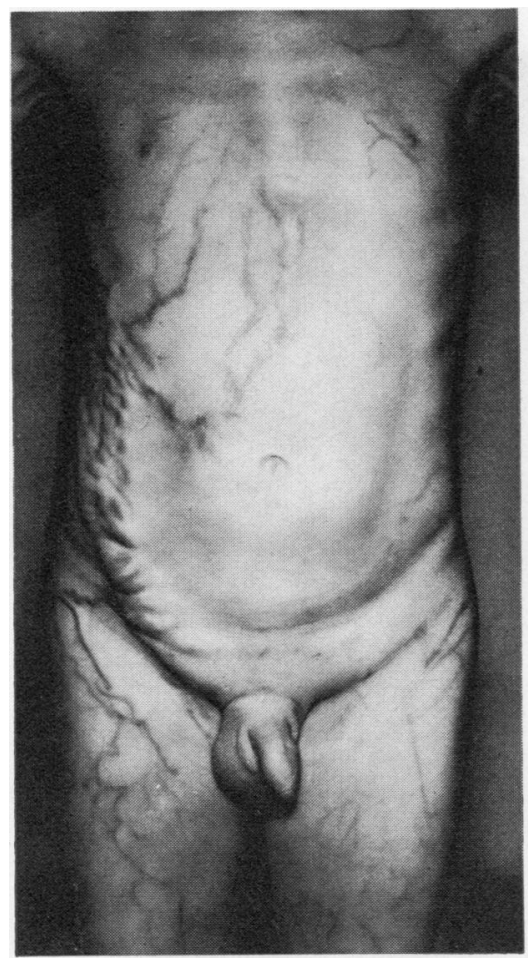

FIG. 1. Infrared photograph showing extensive abdominal varicosities. pressure was $160 / 90 \mathrm{mmHg}$ in both arms. Clinical evidence of right ventricular hypertrophy was noted with an accentuated and widely split second sound in the pulmonary area. No murmurs were heard. The jugular venous pressure was normal and there was no dependent oedema. The liver edge could be felt 1 in $(25.4 \mathrm{~mm})$ below the right costal margin but it was neither tender nor pulsatile. The spleen and kidneys were not palpable. The large varicosities contained fluid blood and were as described above. Vertical linear scars were present in both popliteal fossae. A tentative diagnosis was made of pulmonary hypertension secondary to repeated pulmonary emboli from the lower limbs. In view of the unusual clinical picture steps were taken to reach a more definitive diagnosis. The relevant procedures are listed below.

RADIOGRAPHY Chest radiographs in 1963 showed a small right lower pulmonary artery as compared with that of the left side and there was some pruning of the smaller branches of the right vascular tree. This change had occurred since 1959 when the radiograph presented an essentially normal appearance (Fig. 2). In March 1966 irregular opacities in the right upper lobe were attributed to pulmonary infarcts. These cleared, leaving a little irregular fibrosis (Fig. 3).

Tomography of the hilar regions confirmed the reduced calibre of the vascular pedicle of the right lung.

Pulmonary arteriography revealed complete obstruction of the right pulmonary artery proximal to its bifurcation (Fig. 4) and an engorged appearance of the left lung through which the contrast material flowed naturally.

Opacification of the aortic arch and descending part of the thoracic aorta revealed an enlarged bronchial artery passing to the area of previous infarction. Selective catheterization of the orifice of the bronchial artery proved impossible. No bronchopulmonary shunt was demonstrated (Fig. 5).

LUNG SCANNING Injection of Maa labelled with ${ }^{99} \mathrm{Tc}$ in the supine position showed complete absence of an arteriocapillary bed on the right, whereas there was good and even perfusion of the left lung.

CARDIAC CATHETERIZATION Routine catheterization through the left cubital fossa gave a pressure in the main pulmonary artery of $40 / 10 \mathrm{mmHg}$ and of $58 / 100 \mathrm{mmHg}$ in the right ventricle. Samples of blood at various levels showed no evidence of a left-to-right shunt.

RESPIRATORY FUNCTION TESTS The forced expired volume in one second $\left(\mathrm{FEV}_{1}\right)$ was 1.28 litres and the forced vital capacity (FVC) was 2.52 litres $(59 \%$ of the predicted VC). The $\mathrm{FEV}_{1} / \mathrm{FVC}$ percentage was 51. The peak expiratory flow rate was $2201 \mathrm{l} / \mathrm{min}$ and the CO transfer factor (TF) using the steady state method was $14.5 \mathrm{ml} / \mathrm{min} / \mathrm{mmHg}$ at a minute volume of 14.0 litres (predicted value $25 \mathrm{ml} / \mathrm{min} / \mathrm{mmHg}$ ) and 

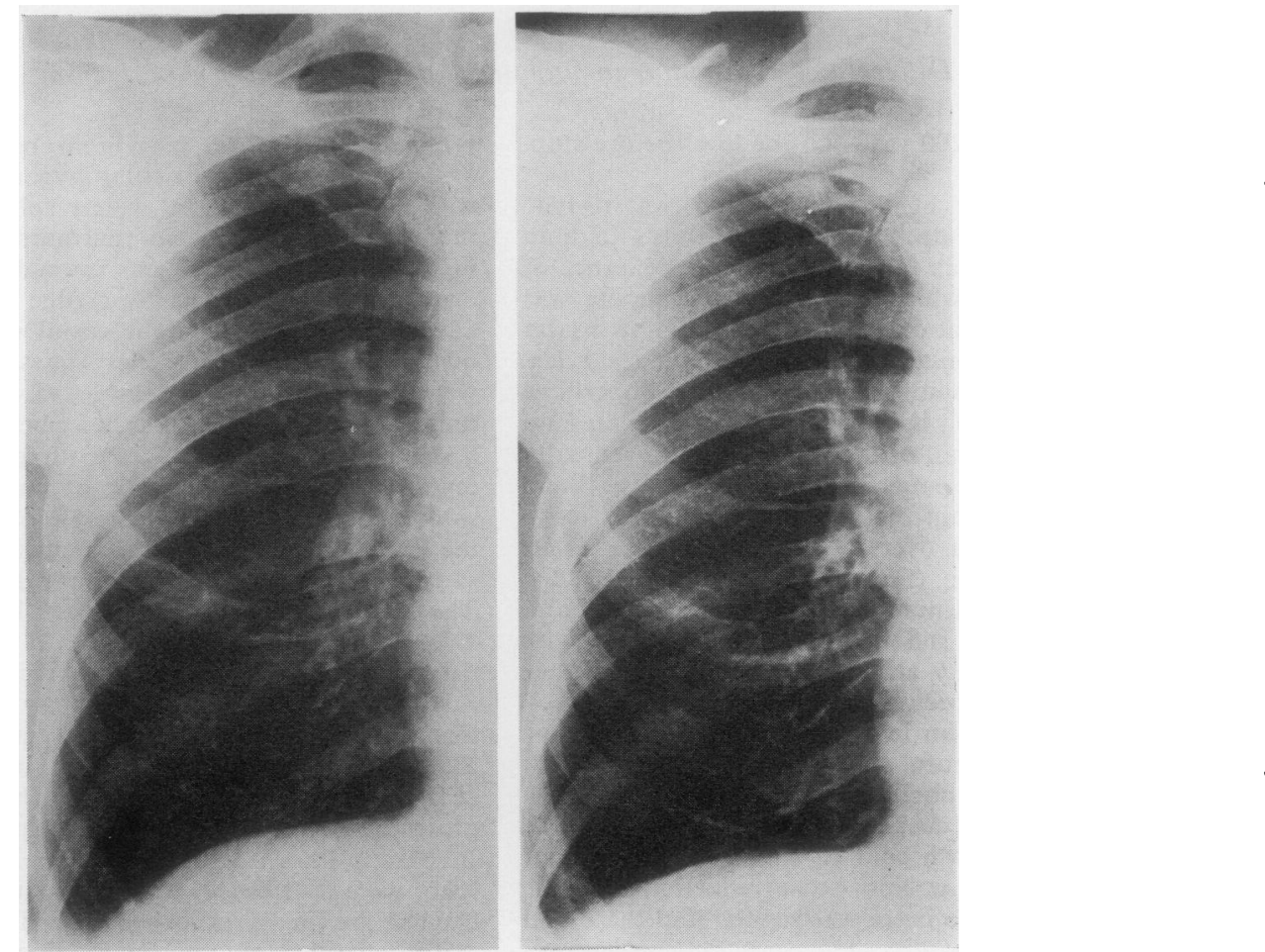

FIG. 2. Chest radiographs in 1959 (left) and 1963 (right) showing the reduction in size of the hilar vessels of the right lung.

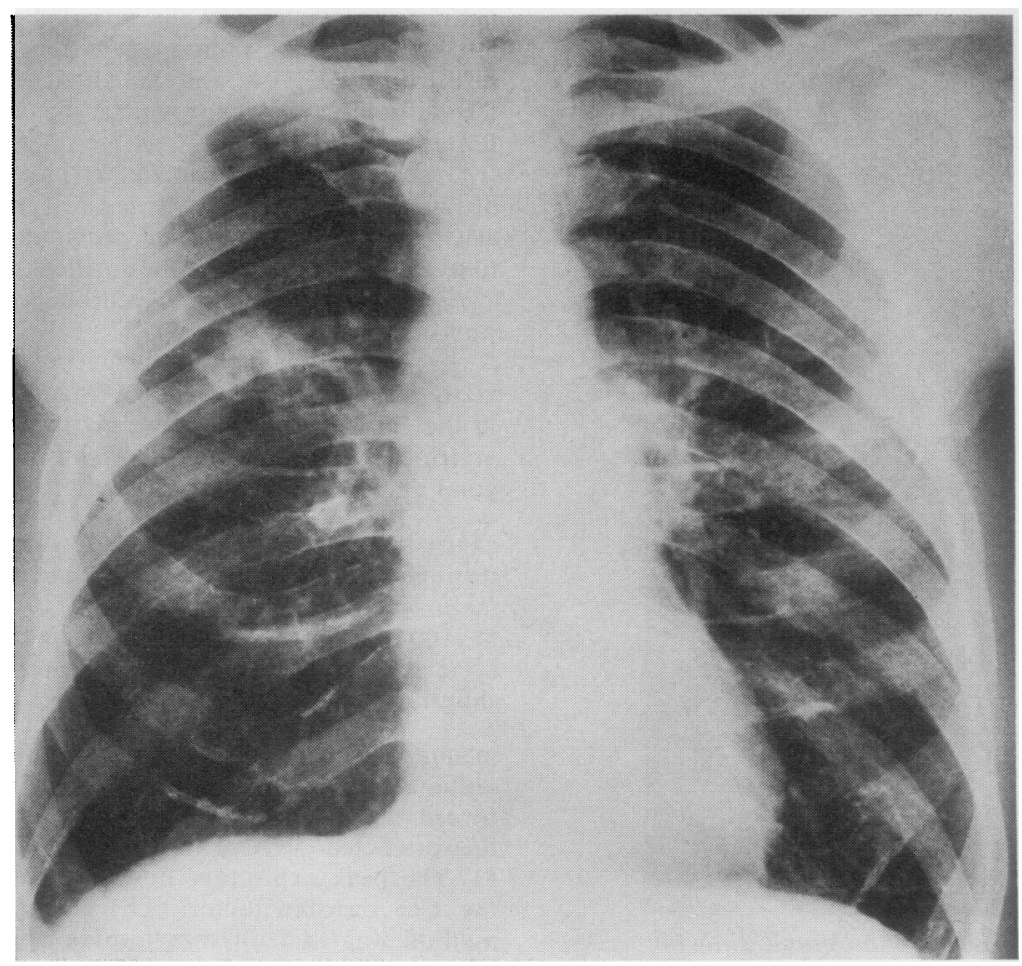

FIG. 3. Chest radiograph in 1966 showing pulmonary infarcts in the right upper lobe. 


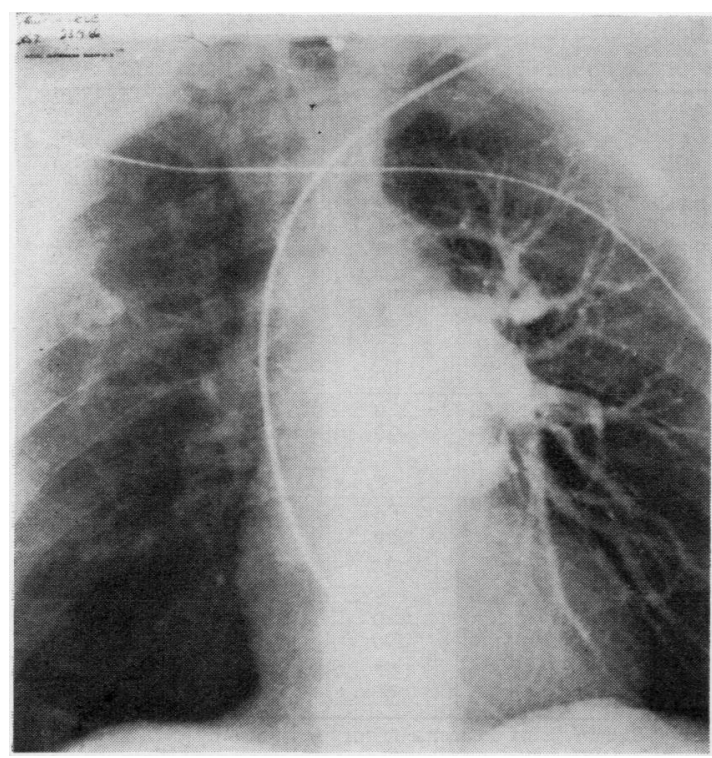

FIG. 4. Pulmonary angiogram showing absence of filling of the right pulmonary artery.

this increased to $17 \cdot 7 \mathrm{ml} / \mathrm{min} / \mathrm{mmHg}$ at a minute volume of 31.6 litres on exercise. The total lung capacity, measured by the helium dilution method, was 6.110 litres with a residual volume/total lung capacity ratio of $54 \cdot 1 \%$. Gas mixing was complete in 3 minutes.

Arterial blood samples showed an oxygen saturation of $89.5 \%$ at rest, $82.5 \%$ on mild exercise, and $91.5 \%$ after breathing oxygen for 30 minutes. The $\mathrm{PaCo}_{2}$ (rebreathing method) was $33 \mathrm{mmHg}$.

It was concluded that there was moderate overall ventilatory impairment of both restrictive and obstructive types. Hyperventilation at rest (minute volume $16 \mathrm{l} / \mathrm{min}$ ) and more so on exercise (minute volume $47 \mathrm{l}$./ $\mathrm{min}$ ) was prominent with a mild reduction in the transfer factor which appeared relatively fixed.

OTHER INVESTIGATIONS Hb $15.9 \mathrm{~g} / 100 \mathrm{ml}$; WBC $5,000 / \mathrm{m}^{3}$; ESR(Westergren) $30 \mathrm{~mm}$ in one hour; serum proteins $7.0 \mathrm{~g} / 100 \mathrm{ml}$, albumin $4.0 \mathrm{~g} / 100 \mathrm{ml}$ and globulin $3.0 \mathrm{~g} / 100 \mathrm{ml}$. Electrophoresis showed a moderate diffuse increase in gamma globulin. Liver function tests were normal apart from an increase in thymol flocculation. Blood urea and electrolytes were normal. The electrocardiogram showed right axis deviation, depression of the ST segment, and inverted $T$ waves in leads $V$ 1-3 together with a dominant $S$ wave in leads V 4 and 5 , consistent with right ventricular strain.

BRONCHOSPIROMETRY The differential ventilation of the two lungs was studied by bronchospirometry.

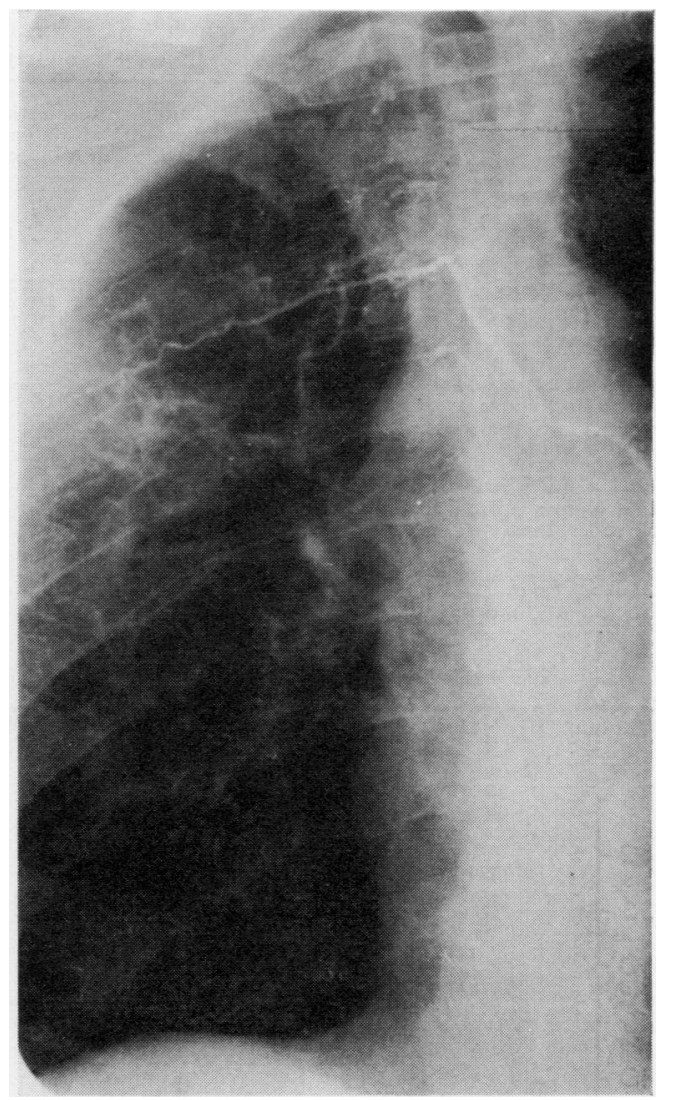

FIG. 5. Bronchial arteriogram showing an enlarged bronchial artery passing to an area of previous infarction.

An indwelling Cournand needle was inserted into a brachial artery. A Carlens catheter was passed after the throat had been sprayed with a local anaesthetic. Each lung was then connected to a spirometer so that spirometric measurements could be made simultaneously but separately for the two lungs. The patient was supine throughout the procedure. The spirometers were filled with air.

A period of several minutes was allowed for the patient to become accustomed to the procedure and forced expiratory volumes were then obtained. The spirometer to the right lung was then filled with $5.8 \%$ carbon dioxide in air while the spirometer to the left lung contained air alone as before. The spirometric measurements were repeated after the patient had been breathing the mixture for 6 minutes. Further measurements were made after a subsequent return to breathing air by both lungs for 6 minutes and again after succeeding 6-minute periods of breathing $14 \%$ oxygen in nitrogen by the right lung only and then air by both lungs. 
T A B L E

VALUES OF TIDAL VOLUME (Vt), MINUTE VOLUME (Ve), FEV ${ }_{2}$, AND PaCo $_{2}$ DURING BRONCHOSPIROMETRY

\begin{tabular}{|c|c|c|c|c|c|c|c|}
\hline & & $\begin{array}{c}\text { Respiration } \\
\text { Rate per } \\
\text { Minute }\end{array}$ & $\begin{array}{l}\text { Vt } \\
(1 .)\end{array}$ & $\begin{array}{l}\mathrm{Ve} \\
(1 . / \mathrm{min})\end{array}$ & $\begin{array}{c}\text { Oxygen } \\
\text { Uptake } \\
(\mathrm{ml} / \mathrm{min})\end{array}$ & $\underset{(1 .)}{\mathrm{FEV}_{1}}$ & $\underset{(\mathrm{mmHg})}{\mathrm{PaCO}_{2}}$ \\
\hline Air to both lungs & $\begin{array}{c}\mathbf{R} \\
\mathbf{L} \\
\text { Total } \\
\text { Total } \\
\end{array}$ & $\begin{array}{l}16 \\
16 \\
-\end{array}$ & $\begin{array}{l}0.389 \\
0.602 \\
0.991 \\
39 \%\end{array}$ & $\begin{array}{r}6 \cdot 22 \\
9 \cdot 63 \\
15 \cdot 85 \\
39 \%\end{array}$ & $\begin{array}{r}0 \\
215 \\
-\end{array}$ & $\begin{array}{l}0.450 \\
0.440 \\
0.890 \\
51 \%\end{array}$ & 26 \\
\hline $\begin{array}{l}\mathrm{CO}_{2} \text { to right lung; } \\
\text { air to left lung }\end{array}$ & 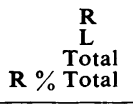 & $\begin{array}{l}16 \\
16 \\
-\end{array}$ & $\begin{array}{l}0.440 \\
0.546 \\
0.986 \\
45 \%\end{array}$ & $\begin{array}{r}7 \cdot 04 \\
8 \cdot 74 \\
15 \cdot 78 \\
45 \%\end{array}$ & $\begin{array}{r}0 \\
435 \\
- \\
\end{array}$ & $\begin{array}{l}0.460 \\
0.370 \\
0.830 \\
56 \%\end{array}$ & 44 \\
\hline Air to both lungs & $\begin{array}{c}\mathbf{R} \\
\mathbf{L} \\
\text { Total } \\
\text { Total }\end{array}$ & $\begin{array}{l}16 \\
16 \\
-\end{array}$ & $\begin{array}{l}0.388 \\
0.518 \\
0.906 \\
43 \%\end{array}$ & $\begin{array}{r}6 \cdot 22 \\
8 \cdot 29 \\
14 \cdot 51 \\
43 \%\end{array}$ & $\begin{array}{r}0 \\
310 \\
\\
\end{array}$ & $\begin{array}{l}0.480 \\
0.420 \\
0.900 \\
54 \%\end{array}$ & 19 \\
\hline $\begin{array}{l}\text { Low oxygen to right lung; } \\
\text { air to left lung }\end{array}$ & $\begin{array}{c}\mathbf{R} \\
\mathbf{L} \\
\mathbf{R} \% \text { Total } \\
\text { Total }\end{array}$ & $\begin{array}{l}16 \\
16 \\
-\end{array}$ & $\begin{array}{l}0 \cdot 378 \\
0 \cdot 602 \\
0 \cdot 980 \\
39 \%\end{array}$ & $\begin{array}{r}6 \cdot 05 \\
9 \cdot 63 \\
15 \cdot 68 \\
39 \%\end{array}$ & $\begin{array}{r}0 \\
290 \\
- \\
\end{array}$ & $\begin{array}{l}0.450 \\
0.430 \\
0.880 \\
51 \%\end{array}$ & 26 \\
\hline Air to both lungs & 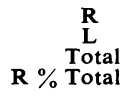 & $\begin{array}{l}17 \\
17 \\
-\end{array}$ & $\begin{array}{l}0.295 \\
0.470 \\
0.765 \\
39 \%\end{array}$ & $\begin{array}{r}5 \cdot 05 \\
8 \cdot 05 \\
13 \cdot 10 \\
39 \%\end{array}$ & $\begin{array}{r}0 \\
190 \\
- \\
-\end{array}$ & $\begin{array}{l}0.450 \\
0.400 \\
0.850 \\
53 \%\end{array}$ & 26 \\
\hline
\end{tabular}

$\mathbf{R}=$ right lung; $\mathrm{L}=$ left lung; Total = total value for the right and left lungs; $\mathbf{R} \%$ Total $=\%$ of a parameter for the right lung
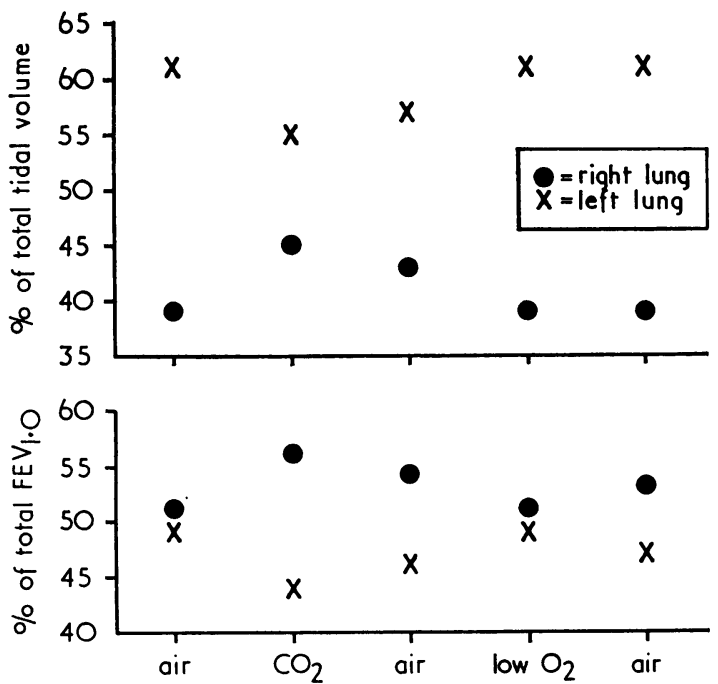

FIG. 6. Distribution of tidal volume and FEV 1 during bronchospirometry.

Samples of arterial blood were taken at the end of each breathing period and were analysed for carbon dioxide tension on a Radiometer instrument.

A chest radiograph was taken at the end of the procedure and this showed that the Carlens catheter was situated correctly at the bifurcation of the trachea. The resistance of the two channels of the catheter was measured using a rotameter and found to be equal.

The results are given in the Table and Figure 6.

The tidal volume $(\mathrm{Vt})$ of the right lung during the initial air breathing period was $389 \mathrm{ml}$; this was only $39 \%$ of the total Vt, $61 \%$ going to the left lung. On breathing carbon dioxide the percentage of the tidal volume going to the right lung increased so that $45 \%$ of the total went to the right lung and $55 \%$ to the left lung. On the return to air breathing the distribution reverted towards the initial pattern, $43 \%$ going to the right lung and $57 \%$ to the left. When the low oxygen mixture was breathed the distribution was identical with that during the first breathing period ( $39 \%$ going to the right lung). On the final return to air breathing the intial pattern was maintained.

The minute volume (Ve) of the two lungs combined was $15.861 . / \mathrm{min}$ during the first air breathing period. There was no significant change in Ve during the carbon dioxide or low oxygen breathing periods but there was a slight reduction during the final air breathing period. The distribution of Ve to the two lungs reflected that of the tidal volume. The respiration rate did not change significantly throughout the study.

The FEV $_{1}$ for both lungs combined was reduced during the first air breathing period; this is consistent with the presence of some airways obstruction although this was not great. The reduction could be accounted for in part by the supine posture of the patient. In the first air breathing period the $\mathrm{FEV}_{1}$ of the two lungs was almost identical. During carbon dioxide breathing the $F E V_{1}$ of the right lung increased slightly.

The arterial carbon dioxide tension $\left(\mathrm{PaCO}_{2}\right)$ was initially $26 \mathrm{mmHg}$ and increased to $44 \mathrm{mmHg}$ during carbon dioxide breathing; there was a return to a low value on the resumption of air breathing and this remained low throughout the rest of the procedure.

The oxygen uptake from the right lung was zero throughout the procedure, but in the left lung the oxygen uptake increased markedly when the right lung was ventilated with carbon dioxide and decreased on the return to air breathing. 
Clinical COURSE Pulmonary endarterectomy was carried out on 6 July 1967. The approach was by standard median sternotomy. The right pleural cavity was opened to reveal extensive dense pleural adhesions. The vena azygos was huge, measuring approximately $2.5 \mathrm{~cm}$ in diameter. Digital exploration of the right atrium confirmed an intact septum and an enlarged superior vena cava but the inferior vena cava appeared to consist of several small luminae. The right pulmonary artery was opened longitudinally and an old thrombus was extracted piecemeal. Eventually a distal cast was withdrawn consisting of part of the superior and inferior divisions. Histologically this showed varying stages of organization with one fragment containing calcification.

The immediate postoperative period was most gratifying and the clinical evidence pointed to revascularization of the right lung. Unfortunately it was not possible to repeat the lung scan. After one week he developed bronchopneumonia which failed to respond to intensive antibiotic therapy. Death occurred on 20 July 1967.

NECROPSY The right lung showed extensive infarction, but the right pulmonary artery was free of clot. The left lung appeared normal but on microscopy showed organized thrombus in many pulmonary arteries and features of pulmonary hypertension.

The inferior vena cava was represented throughout its abdominal course by a thin, fibrous, calcified cord with a very narrow lumen which would just admit a probe. The common iliac and the internal and external iliac veins were of a similar appearance although they were not calcified and had wider lumina. The renal veins were normal until they reached the inferior vena cava when they narrowed abruptly and the lumen was virtually pin-hole.

The opening of the inferior vena cava into the right atrium was small and a very large azygos vein opened into the superior vena cava.

\section{DISCUSSION}

The results show that on all occasions the distribution of ventilation was abnormal; a greater proportion of the tidal volume passed to the left lung than to the right. This is the reverse of the normal distribution.

Ventilation of the right lung alone with carbon dioxide resulted in a change in distribution so that the ventilation of the right lung increased and that in the left lung decreased, the shift being towards the normal pattern. Although the distribution did not become completely normal there was a trend in this direction which was reversed on the re- sumption of air breathing. The results are consistent with the presence of an initially increased airways resistance in the right lung which was reversed by carbon dioxide; this is in agreement with the findings of Severinghaus et al. (1961) and Swenson et al. (1961). The relatively small change in tidal volume during carbon dioxide inhalation may have been because this was given for a 6minute period only. Similarly, the failure of the tidal volume of the right lung to return to preexisting levels during the second air breathing period may have been due to insufficient time being allowed for adequate clearance of carbon dioxide from the lung. The changes in $\mathrm{FEV}_{1}$ were small but may have reflected a change in airways resistance.

Low carbon dioxide tensions have been found to constrict the airways of animals (Löhr, 1924; Wick, 1952) and the administration of carbon dioxide has been found to dilate them (Tiefensee, 1929; Duke, 1950; Nisell, 1951; Samanek and Aviado, 1967). Astin, Barer, Shaw, and Warren (1971) have shown a bronchodilator action of carbon dioxide in cats and dogs when bronchial tone is high from several different causes. In man a reduction in alveolar carbon dioxide tension due to hyperventilation has been reported to increase pulmonary and airways resistance (Newhouse, Becklake, Macklem, and McGregor, 1964; Sterling, 1968): the increase in resistance was prevented by the inhalation of carbon dioxide during hyperventilation. There is thus some evidence that carbon dioxide has a bronchodilator action although other investigators have found it to constrict airways in animals (Trendelenberg, 1912; Green and Widdicombe, 1966). Shaw (1970) has shown that carbon dioxide can have both dilating and constricting actions on the pulmonary vasculature of rats. Carbon dioxide may similarly have two actions on the airways, depending perhaps on the initial degree of airway constriction.

The increase in the oxygen uptake of the left lung when the right lung was ventilated with carbon dioxide is of interest. Since there was no increase in minute volume this must have been due to a change in the pulmonary circulation of the left lung and could be accounted for by vasodilatation induced by the raised $\mathbf{P c O}_{2}$ during this period.

The rise in systemic arterial carbon dioxide tension when the right lung only was ventilated with carbon dioxide indicates that although the pulmonary arterial circulation was occluded there must have been a significant collateral circulation flowing through the right lung; this was pre- 
sumably derived from the bronchial arteries (Cudkowicz et al., 1960); an enlarged bronchial artery had been demonstrated in this patient by bronchial arteriography.

The patient was hyperventilating during the first air breathing period and throughout the rest of the investigation. This is consistent with the presence of extensive pulmonary embolism associated with hypoxia and accounts for the reduced arterial $\mathrm{PCO}_{2}$. The increased minute volume was due to an increased tidal volume since the respiration rate was only 16 per minute. The inhalation of carbon dioxide by the right lung increased the $\mathrm{PaCO}_{2}$ but there was no corresponding increase in minute volume. This failure to increase ventilation may have been due to the fact that the initial $\mathrm{PaCO}_{2}$ was low and the rise in $\mathrm{PaCO}_{2}$ brought the level only to within the normal range at $44 \mathrm{mmHg}$. Since there was no increase in $\mathrm{PaCO}_{2}$ above the normal level, there was no increase in ventilation.

Ventilation of the right lung with a low oxygen mixture in the present study failed to alter the distribution of ventilation; this differs from the experimental findings in dogs (Severinghaus et al., 1961 ) in which ventilation with a low oxygen mixture prevented the reduction in ventilation associated with pulmonary artery occlusion.

These results confirm that changes in the distribution of ventilation occur in man following pulmonary artery occlusion by embolism. They show that, as in experimental studies, the distribution can be altered by the inhalation of carbon dioxide. The results are compatible with a bronchodilator action of carbon dioxide in man.

We wish to thank Dr. F. N. Holden for details of the early stages of the illness, Mr. Desmond Taylor for performing the embolectomy, Drs. N. Lewtas and G. Sandler for radiological studies, Dr. D. Fernandez for the necropsy study, and Mr. R. Saynor for technical assistance.

\section{REFERENCES}

Astin, T. W., Barer, G. R., Shaw, J. W., and Warren, P. (1971). The bronchodilator action of carbon dioxide. J. Physiol. (Lond.), 215, 33P.

Bergan, F. (1952). The relative function of the lungs in supine, left and right lateral position. J. Oslo. Cy Hosp., 2, 185.

Bjorkman, S. (1934). Bronchospirometrie. Eine klinische Methode die Funktion der menshlichen Lungen getrennt und gleichzeitig zu untersuchen. Acta med. scand., Suppl. 56.

Cudkowicz, L., Abelmann, W. H., Levinson, G. E., Katznelson, G., and Jveissaty, R. M. (1960). Bronchial arterial blood flow. Clin. Sci. 19, 1.

Davison, P. H., Armitage, G. H., and Mcllveen, D. J. S. (1956). Chronic cor pulmonale due to silent pulmonary embolism. Lancet, 2, 224.

Duke, H. N. (1950). The action of carbon dioxide on isolated perfused dog lungs. Quart. J. exp. Physiol., 35, 25.
Gaensler, E. A., and Cugell, D. W. (1952) Bronchospiro- $\overrightarrow{\bar{F}}$ metry. V. Differential residual volume determination. $\mathscr{\omega}$ J. Lab. clin. Med., 40, 558.

Green, M., and Widdicombe, J. G. (1966). The effects of $\frac{C}{\sigma}$ ventilation of dogs with different gas mixtures on air- $\overline{\bar{s}}$ way calibre and lung mechanics. J. Physiol. (Lond.), 186, 363.

Lillington, G. A., Fowler, W. S., Miller, R. D., and Helmholz, H. F. jr. (1959). Nitrogen clearance rates of right कs and left lungs in different positions. J. clin. Invest., 38, $\overrightarrow{0}$ 2026.

Löhr, H. (1924). Untersuchungen zur Physiologie und $\vec{\omega}$ Pharmakologie der Lunge. Z. ges. exp. Med., 39, 67.

Moore, R. L., Humphreys, G. H., and Cochran, H. W. (1934). The effect of sudden occlusion of either primary branch of the pulmonary artery on cardiac output and pulmonary $N$ expansion. J. thorac. Surg., 3, 573.

Newhouse, M. T., Becklake, M. R., Macklem, P. T., and McGregor, M. (1964). Effect of alterations in end-tidal $\infty$ $\mathrm{CO}_{2}$ tension on flow resistance. J. appl.Physiol., 19, 745 .

Nisell, O. L. (1951). The influence of oxygen and carbon dioxide on the bronchioles and vessels of the isolated perfused lungs. Acta physiol. scand. 23, 352.

Sadoul, P., Faivre, G., Gilgenkrantz, J. M., Cherrier, F., and Saunier, C. (1962). Étude de la fonction respiratoire dans le coeur pulmonaire chroniqe post-embolique. $J$. franc. Med. Chir. thor., 16, 433.

Samanek, M., and Aviado, D. M. (1967). Interrelationships between pulmonary blood flow and bronchomotor tone: $\mathrm{Po}_{2}$ and $\mathrm{PCO}_{2}$. J. appl. Physiol., 22, 719 .

Scholzman, D. L., Kerby, G. R., and Ruth, W. E. (1971). Chronic pulmonary artery thrombosis with features of unilateral hyperlucent lung syndrome. Amer. J. Med., 50, 547.

Severinghaus, J. W., Swenson, E. W., Finley, T. N., Lategola, $\overrightarrow{\bar{O}}$ M. T., and Williams, J. (1961). Unilateral hypoventilation produced in dogs by occluding one pulmonary artery. J. appl. Physiol., 16, 53.

Shaw, J. W. (1970). Direct evidence for a dilator action of carbon dioxide in pulmonary vessels when vascular tone is high. J. Physiol. (Lond.), 207, 75P.

Sterling, G. M. (1968). The mechanism of bronchoconstriction due to hypocapnia in man. Clin. Sci., 34, 277.

Svanberg, L. (1957). Influence of posture on the lung volumes, ventilation and circulation in normals. A spirometric-bronchospirometric investigation. Scand. clin. J. Lab. Invest, 9, suppl 25.

Swenson, E. W., Finley, T. N., and Guzman, S. V. (1961). Unilateral hypoventilation in man during temporary occlusion of one pulmonary artery. J. clin. Invest., 40,828.

Tiefensee, K. (1929). Pharmakologische Studien an der Bronchialmuskulatur. II. Mitteilung: Über die Bedeutung der Blutbeschaffenheit für den Tonus der Bronchial- o muskeln und ihr Ansprechen auf Gifte. Arch. Exp. N path. Pharmakol., 139, 139.

Trendelenberg, P. (1912). Physiologische und pharmakologische Untersuchungen an der isolierten Bronchial- $O$ muskulatur. Arch. Exp. path. Pharmakol., 69, 79.

Venrath, H., Rotthoff, R., Valentin, H., and Bolt, W. (1952). Bronchospirographische Undersuchungen bei Durch- $\mathbb{D}$ blutungsstörungen im kleinen Kreislauf. Beitr. Klin. Tuberk., 107, 291.

Wick, H. (1952). Die Beeinflussung der Tracheobronchial-und alveolarweite durch lokale Einwirkung des Kohlen- $\overparen{D}$ dioxyds. Arch int. Pharmachodyn., 88, 461.

Wilhelmsen, L., Selander, S., Söderholm, B., Paulin, S., $\Omega$ Varnauskas, E., and Werko, L. (1963). Recurrent pulmonary embolism. Medicine (Baltimore), 42, 335. 